\title{
Evaluation of High Sensitive Cardiac Troponin I as A Marker of Myocardial Injury in Children with Congenital Heart Disease Mohamed Mamdouh Gaafar ${ }^{1}$, Eman M. EIMoghazy ${ }^{1}$, Nagwa Mohamed Shawky ${ }^{2}$, Mona Mohamed Abdelkhalek Elsayed ${ }^{1}$ \\ ${ }^{1}$ Department of Pediatrics, ${ }^{2}$ Department of Clinical Pathology, Faculty of Medicine - Zagazig University
}

\begin{abstract}
Background: Congenital heart diseases are abnormalities of the heart and/or great vessels present at birth. $1 \%$ of live births have a congenital heart defect. Cardiac Troponin, especially cardiac Troponin I (cTnI), are the preferred biomarkers for the detection of cardiac injury. International cardiology and laboratory medicine guidelines recommend highly sensitive Tn1 (hscTnI) that has excellent precision $(<10 \%)$. hsTnI is a cheap way that is capable of accurately and precisely detecting low levels of Troponin I enabling treatment and allowing earlier definitive diagnosis of acute myocardial injury than is currently possible.

Objectives: Evaluation of the myocardial injury as detected by highly sensitive cardiac Troponin I (hscTnI) in children with left to right shunt.

Patients and methods: This cross-sectional study was conducted on 48 patients with congenital heart diseases (CHD) whether cyanotic or acyanotic diagnosed clinically and by echocardiography admitted to Cardiology Unit of Pediatric Department, Zagazig University Hospitals from June 2017 to December 2017. Their ages ranged from 2 months to 4 years. hscTnI assay was performed for all patients.

Results: The study revealed that patients' group with CHD with left to right shunt had high level of hscTnI with a median range from $1.7-237.00 \mathrm{ng} \mathrm{ml}$.

Conclusion: Serum Troponin I levels were high in children with CHD with left to right shunt, which may indicated underlying myocardial injury.
\end{abstract}

Keywords: Pediatrics, Heart, Troponin I.

\section{INTRODUCTION}

Congenital heart disease represents a major health problem and most common cause of congenital anomalies ${ }^{(\mathbf{1})}$. The estimated prevalence reaches up to 10 per 1000 live births. Congenital heart defects are divided into two main groups; cyanotic and acyanotic heart disease ${ }^{(2)}$.

Most CHD have specific hemodynamics, including volume and pressure overload as well as cyanosis \& pulmonary hypertension (HPN), which cause myocardial Injury by activation of neurohormones \& inflammatory cytokines ${ }^{(3)}$.

Cardiac troponins (cTnI) are considered the preferred and gold standard biomarker for myocardial injury as it detects subclinical injury ${ }^{(4)}$. Troponin is a complex of three regulatory proteins (troponin c, troponin $\mathrm{T}$, troponin I) that is integral to muscle contraction in skeletal and cardiac muscle ${ }^{(5)}$. Cardiac troponins are not expressed outside cardiac tissue ${ }^{(6)}$. Ischemic and non-ischemic cardiac injury release cTnI in circulation which may be due to cardiomyocyte death ${ }^{(7)}$.

Evaluation of hemodynamic load and myocardial injury can be done by cardiac troponin in children with CHD ${ }^{(8)}$. Recently a second generation cTnI assay has become available. The accuracy of diagnosis of myocardial injury increased by assessment of this group of sensitive troponin as the first-generation troponin has some limitation as circulating troponin increased lately after onset of injury ${ }^{(9)}$. Highly sensitive cardiac troponin assay allows detection of 10-fold lower concentration of cardiac troponin ${ }^{(\mathbf{1 0})}$. We aimed to study the level of HscTnI in children with CHD as a predictor of myocardial injury.

\section{PATIENTS AND METHODS}

This cross-sectional study included 48 infants and children their ages ranged from two months to four years and all cases with CHD were diagnosed clinically and by echocardiography and admitted to Cardiology Unit of Pediatric Department, Zagazig University Hospitals during the period from June 2017 to December 2017.

\section{Ethical approval:}

A signed written informed consent was taken from parents of each case. The study was approved by our Ethical Committee.

\section{Inclusion Criteria:}

- Children with congenital heart disease whether cyanotic or non-cyanotic.

- Age From 2 months to 4 years from both sexes.

\section{Exclusion Criteria:}

- Infant less than 2 months of age were excluded from the overall analysis because serum cTnI level abruptly increase immediately after birth followed by gradual decrease. 
- Infant and children with any condition or disease which may affect cardiac hemodynamics or functions other than congenital heart disease including infective endocarditis, chronic renal or lung failure, children taking cardiotoxic drugs and critically ill children.

\section{Methods:}

\section{All patients in this study were subjected to:}

\section{1- Full history taking including:}

- Personal history: Name, age (date of birth), sex, residence and order in family.

- Present history for data about the congenital heart defect: Cough expectoration, dyspnea, orthopnea, paroxysmal nocturnal dyspnea, edema, cold extremities, tachypnea with feeding difficulties, cyanosis (permanent or attacks) and hyper cyanotic spells.

- Complaint: shortness of breath, tachypnea, difficult feeding, bluish discoloration and tachycardia.

- Past history: Perinatal: prenatal (infection, drugs and diseases), natal (weight and gestational age) and postnatal (cyanosis).

- Dietetic history: feeding difficulties and poor weight gain.

- Family history: Consanguinity.

\section{2- $\quad$ Full Clinical Examination}

General conditions: appearance, consciousness and decubitus. Vital signs such as temperature, respiratory rate, blood pressure, heart rate and pallor.

Regional examination:

- Head: sutures, face, eye and mass.

- Upper limb: clubbing, skin and muscles.

- Neck: trachea, mass and veins.

- Lower limb: edema, peripheral pulsations and ulcer,

- Back: sacral edema and nodules.

- Cardiac examination: Inspection: precordial bulge, pulsations pigmentations, scars and dilated neck veins. Palpation: Thrill and pulsations. Auscultation: Heart sounds, murmur and additional heart sounds. Auscultation of chest: crepitations, wheezes, decrease air entry and bronchitis.

3- Radiological findings: Chest X-ray to detect cardiomegaly and/or pneumonia, echocardiography for accurate diagnosis of the CHD

\section{4- Laboratory investigations:}

\section{Cardiac Enzymes:}

Two $\mathrm{ml}$ of blood were taken from each child after echocardiography and collected in procoagulation tube with routine procedure. Measurement of Troponin I was applied for all samples.

\section{Method of cardiac troponin I measurement:}

Cardiac troponin I is estimated using VIDAS ${ }^{\circledR}$ high sensitive troponin I (TNHS). VIDAS ${ }^{\circledR}$ high sensitive troponin I is an automated quantitative test for use on the instruments of the VIDAS $®$ family for the determination of human cardiac troponin $I$ in human serum or plasma using the ELFA technique (Enzyme Linked Fluorescent Assay).

\section{Principle:}

The assay principle combines a one-step enzyme immunoassay sandwich method with a final fluorescent detection (ELFA). The Solid Phase Receptacle (SPR $®$ ) serves as the solid phase as well as the pipetting device. Reagents for the assay are ready-to-use and pre-dispensed in the sealed reagent strips.

\section{Steps:}

All of the assay steps were performed automatically by the instrument:

- The sample was transferred into the wells containing alkaline phosphatase-labeled anticardiac troponin antibodies (conjugate).

- The sample/conjugate mixture was cycled in and out of the SPR® several times.

This operation enables the troponin I to bind with the immunoglobulins fixed to the interior wall of the SPR ${ }^{\circledR}$ and the conjugate to form a sandwich. Unbound components are eliminated during washing steps. During each step, the substrate (4-Methylumbelliferyl phosphate) was cycled in and out of the SPR®. The conjugate enzyme catalyzes the hydrolysis of this substrate into a fluorescent product (4-Methyl-umbelliferone), the fluorescence of which is measured at $450 \mathrm{~nm}$. The intensity of the fluorescence is proportional to the concentration of antigen present in the sample.

At the end of the assay, the results were automatically calculated by the instrument in relation to two calibration curves stored in memory corresponding to the two detection steps. A fluorescence threshold value determines the calibration curve to be used for each sample. The results were then printed out.

\section{Sample-related interference:}

It is recommended not to use samples that are hemolyzed, lipemic, or icteric. The VIDAS ${ }^{\circledR}$ high sensitive troponin I assay measurement range extends from 4.9 to $40000 \mathrm{ng} / \mathrm{L}$.

\section{Limits of detection and quantitation:}

- Limits of Blank (LOB); are between 0 and 1.9 $\mathrm{ng} / \mathrm{L}$.

- Limits of Detection (LOD); are between 1.3 and $3.2 \mathrm{ng} / \mathrm{L}$.

- Limits of Quantitation (LOQ); are between 2.9 and $4.9 \mathrm{ng} / \mathrm{L}$. 
Normal range: The normal range is recommended as $<0.01 \mathrm{ng} / \mathrm{ml}$.

\section{Statistical analysis}

The collected data were analyzed by computer using Statistical Package of Social Services version 22 (SPSS). Data were represented in tables and graphs. Continuous quantitative variables e.g. age were expressed as the mean \pm SD \& median (range). Categorical qualitative variables were expressed as absolute frequencies (number) \& relative frequencies (percentage). Suitable statistical tests of significance were used after checked for normality. The results were considered statistically significant when the significant probability was less than 0.05 ( $\mathrm{P}<0.05)$. $\mathrm{P}$-value $<0.001$ was considered highly statistically significant (HS), and P-value $\geq 0.05$ was considered statistically insignificant (NS).

\section{RESULTS}

Table (1): Demographic data of the studied children $(\mathrm{N}=48)$

\begin{tabular}{|c|c|c|}
\hline \multirow{2}{*}{ Demographic data } & \multicolumn{2}{|c|}{$\begin{array}{c}\text { Studied children } \\
(\mathrm{N}=48)\end{array}$} \\
\hline & No. & $\%$ \\
\hline Age: mean \pm SD & \multicolumn{2}{|c|}{$15.06 \pm 9.24$} \\
\hline \multicolumn{3}{|l|}{ Sex: } \\
\hline Males & 24 & 50.0 \\
\hline Females & 24 & 50.0 \\
\hline \multicolumn{3}{|l|}{ Residence: } \\
\hline • Rural & 28 & 58.3 \\
\hline - Urban & 20 & 41.7 \\
\hline
\end{tabular}

Table (1) showed that the mean age of the studied group is $15.06 \pm 9.24$ months old, with a range from 3 months to 4 years old. Half of the studied group are male and more than half of them are residents of rural areas $(58.3 \%)$.

Table (2): Highly sensitive cardiac troponin I level among the studied children

\begin{tabular}{|c|c|c|}
\hline \multirow[t]{2}{*}{ Item } & \multicolumn{2}{|c|}{$\begin{array}{c}\text { Studied children } \\
(\mathrm{N}=48)\end{array}$} \\
\hline & No. & $\%$ \\
\hline \multicolumn{3}{|l|}{ Hs-cTnT (ng/mL) (N=48) } \\
\hline Median (Range) & 15.1 & $37.00)$ \\
\hline \multicolumn{3}{|l|}{ Hs-cTnT (ng/mL) } \\
\hline $\begin{array}{l}\text { - } \begin{array}{l}\text { Undetected } \\
\mathrm{ng} / \mathrm{ml}\end{array} \\
\end{array}$ & 14 & 29.2 \\
\hline $\begin{array}{l}\text { - More than } 1.5 \\
\mathrm{ng} / \mathrm{ml}\end{array}$ & 34 & 70.8 \\
\hline
\end{tabular}

Table (2) showed that the mean of Hs-cTnT among the studied group is $46.7 \pm 62.5 \mathrm{ng} / \mathrm{dl}$, with a range from 1.7-237.00 ng/dl. Regarding classification according to presence of Hs-cTnT in serum level is undetected $<1.5 \mathrm{ng} / \mathrm{dl}$ in $(29.2 \%)$ of the studied group.
Table (3): ECHO findings among the studied children

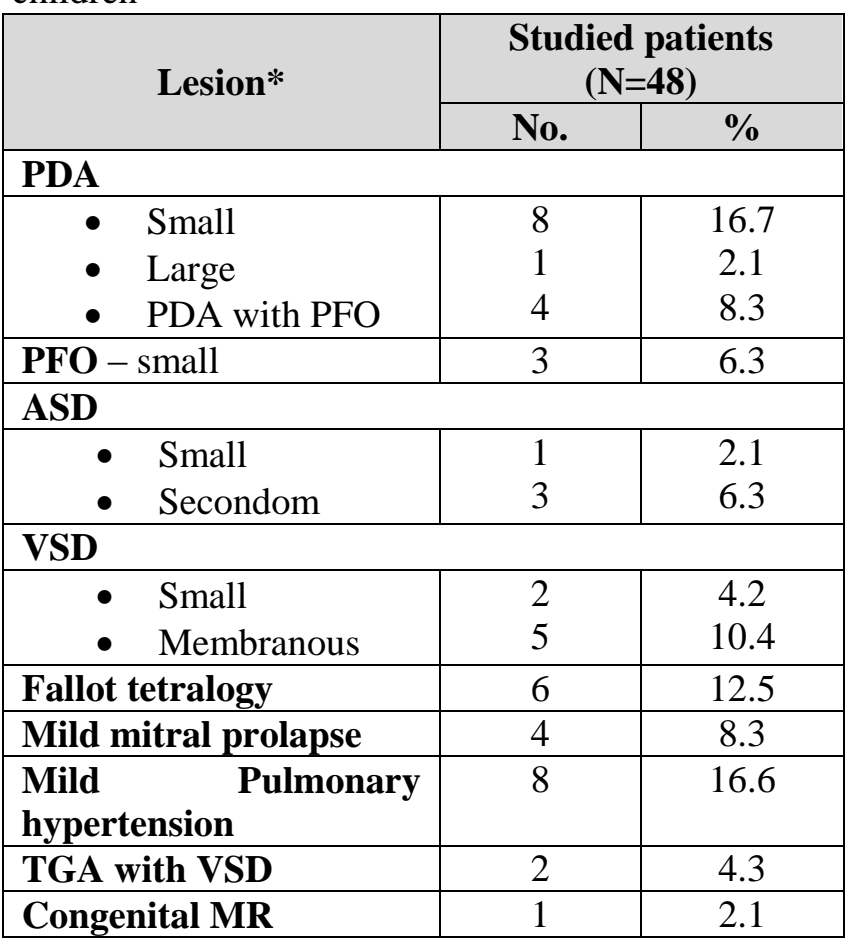

* Multiple lesions were found

Table (3) showed that small PDA, Fallot tetralogy and membranous VSD are the highest congenital cardiac lesions among the studied children (16.7\%, $12.5 \%$ and $10.4 \%$ respectively), while congenital MR is found in only $2.1 \%$ of studied cardiac children.

Table (4): Cardiac lesions among the studied children

\begin{tabular}{|c|c|c|}
\hline \multirow{2}{*}{ Item } & \multicolumn{2}{c|}{$\begin{array}{c}\text { Studied patients } \\
(\mathbf{N}=\mathbf{4 8})\end{array}$} \\
\cline { 2 - 3 } & No. & \% \\
\hline Acyanotic cardiac lesions \\
\hline$\bullet \quad$ PDA & 13 & 27.1 \\
\hline$\bullet \quad$ PFO & 7 & 14.6 \\
\hline$\bullet$ ASD & 4 & 8.6 \\
\hline$\bullet \quad$ VSD & 9 & 18.8 \\
\hline Cyanotic cardiac lesions \\
\hline - Fallot tetralogy & 6 & 12.5 \\
\hline$\bullet \quad$ TGA & 2 & 4.3 \\
\hline
\end{tabular}

Table (4) showed that PDA and VSD are the highest acyanotic congenital cardiac lesions among the studied children (27.1\% and $18.8 \%$ respectively). As regards cyanotic cardiac lesions, Fallot tetralogy is found 3 times more than TGA $(12.5 \%$ and $4.3 \%$ respectively) among the studied cardiac children. 
Table (7): Highly sensitive cardiac troponin I level in serum in relation to cardiac lesions, cardiomegaly, increased broncho-vascular markings and pulmonary hypertension among the studied children

\begin{tabular}{|l|c|c|c|c|}
\hline \multicolumn{1}{|c|}{ Hs-cTnT (ng/mL) } & Acyanotic & Cyanotic & M.W. & P-value \\
\hline Median (Range) & $6(1.5-237)$ & $38.5(2.3-130)$ & 9.5 & $0.002^{*}$ \\
\hline & $\begin{array}{c}\text { Cardiomegaly } \\
(\mathbf{N}=\mathbf{1 7})\end{array}$ & $\begin{array}{c}\text { No cardiomegaly } \\
(\mathbf{N}=\mathbf{1 5})\end{array}$ & & \\
\hline Median (Range) & $15(5-170)$ & $15(1.7-237)$ & 0.14 & 0.74 \\
\hline $\begin{array}{l}\text { Increased broncho- } \\
\text { vascular markings }\end{array}$ & Yes $(\mathrm{N}=11)$ & No $(\mathrm{N}=21)$ & & \\
\hline \multirow{2}{*}{ Pulmonary hypertension } & $15(7-170.7)$ & $15(1.7-237)$ & 0.14 & 0.74 \\
\cline { 2 - 5 } & Yes $(\mathrm{N}=23)$ & No $(\mathrm{N}=25)$ & & \\
\hline \multirow{2}{*}{$\begin{array}{l}\text { Ejection fraction } \\
\text { Median (Range) }\end{array}$} & $15.2(1.5-237)$ & $10(1.3-170.7)$ & 8.58 & $0.014^{*}$ \\
\cline { 2 - 5 } & Low $(\mathrm{N}=5)$ & Normal $(\mathrm{N}=43)$ & & \\
\hline
\end{tabular}

M.W.: Mann-Whitney test, $* \mathrm{P}<0.05$ is significant.

\section{DISCUSSION}

Measuring biomarker levels facilitates the prediction of these pathological changes and provides information about the stress placed on the myocardial cells, the severity of the damage, the responses of neurohumoral factors and the remodeling of the ventricle. Compared to the ample information on cardiac biomarkers in adult heart diseases, data from children with CHD are still limited ${ }^{(3)}$.

Cardiac troponin (cTn) is a well-known, sensitive cardiac biomarker of acute coronary syndrome and acute myocardial infarction (11). The present study was carried out to study the level of highly sensitive cardiac troponin I in children with CHD as a predictor of myocardial Injury. Our study was held on 48 patients who were suffering from congenital heart diseases with a mean age of $15.06 \pm$ 9.24 months with a range from 3 months to 4 years and equal male to female ratio, $58.3 \%$ of the patients live in rural areas and $41.7 \%$ live in urban areas.

Highly sensitive cardiac troponin I was detected in about $70.8 \%$ of our cases denoting myocardial injury among these cases. The mean value among cases was $46.7 \pm 62.5 \mathrm{ng} / \mathrm{ml}$. In agreement with our results, Sugimoto et al. ${ }^{(3)}$ evaluated HsTnI level in children with CHD and left-to-right shunt. They found an increased serum cTnI level in children with CHD. Possible explanation for this high incidence of elevated HsTnI level in the current study is that in Egypt and other developing countries, surgical correction of CHD is delayed due to limited resources which makes the patients are more susceptible to more harm from prolonged exposure of cardiac muscle to pressure and volume overloads giving rise to a high incidence of myocardial affection ${ }^{(\mathbf{1 2})}$.
Our cases were investigated for the lesion of congenital heart diseases and revealed that multiple lesions were found in combination with each other. In contrast to our study, Ghaderian et al. ${ }^{(13)}$ found that isolated lesions were more than multiple lesions. Most of the cases were a-cyanotic with high incidence of PDA $27.1 \%$ followed by VSD $18.8 \%$ then PFO and ASD $14.6 \%$ and $8.6 \%$ respectively. Our study agrees with Ghaderian et al. ${ }^{(13)}$ study, in which VSD, PDA and ASD were the most common heart defects with percentages of $69 \%, 17 \%$ and $10 \%$ of total patient respectively. The cyanotic congenital heart lesions were represented in Fallot tetralogy $12.5 \%$ of cases and TGA $4.3 \%$. This is near to Hafez et al. ${ }^{(12)}$ results, which studied myocardial injury in children with unoperated congenital heart diseases and revealed that VSD and PDA had same incidence rate of $37 \%$ of cases for each followed by ASD 25\% among acyanotic cases, while TGA to Fallot tetralogy ratio was $1: 1$.

Our study showed that membranous VSD represented $71.4 \%$ and muscular VSD were $28.5 \%$, that agree with Brickner et al. ${ }^{(14)}$, who reported that membranous VSD is the commonest type of VSD and ASD secondum represented $75 \%$ and ASD premium were $25 \%$. Also, they reported that the ostium secondum atrial septal defect is the most common type of atrial septal defect and comprises 6-10\% of all CHD.

Chest x-ray done for all patients showed that $13 \%$ had oligemic lung fields and other $13 \%$ of cases had cardiomegaly, plethoric lung \& increased broncho-vascular markings, while $37 \%$ had normal lung. The median value of HsTnI in acyanotic heart lesion was $6 \mathrm{ng} / \mathrm{ml}$ which was significantly lower than cyanotic heart lesion that showed median level 38.5 
$\mathrm{ng} / \mathrm{ml}$. This is against Hafez et al. ${ }^{(\mathbf{1 2})}$ who found that the prevalence was $82.5 \%$ in acyanotic group and $77.5 \%$ in cyanotic group with no significant difference between both groups.

In the present study, 17 patients had cardiomegaly and when compared to the other group of patients who hadn't developed cardiomegaly regarding HsTnI level, there was no significant difference between both. Increased broncho-vascular marking was present in 11 patients but there was no significant difference in serum $\mathrm{HsTnI}$ level in relation to this.

In our study, $48 \%$ of cases developed pulmonary hypertension compared to $52 \%$ of patients had no pulmonary hypertension. When both groups were compared regarding serum HsTnI level, it showed significant higher levels in the pulmonary hypertension group. Our results are in line with Heresi et al. ${ }^{(15)}$ study which was carried out on patients with pulmonary arterial hypertension and found that elevated plasma cTnI, even at subclinical detectable levels, is associated with more severe disease and worse outcomes in patients with pulmonary arterial hypertension.

In the present study, the median $\mathrm{HsTnI}(\mathrm{ng} / \mathrm{mL})$ among the children was not significantly different in patients with low ejection fraction than that in patients with normal ejection fraction. In agreement to our results, Korraa et al. ${ }^{(16)}$ who studied the relation of cardiac troponin levels to the echo radiographic findings and found no significant difference between ejection fraction and cardiac troponin. On the other side, El-Khuffash et al. ${ }^{(17)}$ study which searched the reflection of cardiac troponin over myocardial functions in preterm patients is against to our results as they found that there was significant relation between cardiac troponin and ejection fraction. This may be accused to that all the patients in this study developed PDA.

Our study showed a high incidence of myocardial injury in children with CHDs, which suggested ongoing subclinical myocyte degeneration associated with deterioration of the patients' clinical status. The use of cardiac troponin for follow-up of children with unoperated CHDs may help early detection of myocardial injury and help early management of these cases ${ }^{(\mathbf{3})}$.

\section{CONCLUSION}

Serum Troponin I (hsTnI) levels were high in children with congenital heart diseases with left to right shunt, which may indicate underlying myocardial injury.

\section{REFERENCES}

1. Van D, Konings E, Slager M et al. (2011): Birth Prevalence of Congenital Heart Disease Worldwide. J Am Coll Cardiol., 58 (21): 2241-2247.

2. Warnes C, Liberthson R, Danielson G et al. (2001): Task Force 1: the changing profile of congenital heart disease in adult life. J Am Coll Cardiol., 37 (5): 11701175.

3. Sugimoto M, Ota K, Kajihama A et al. (2011): Volume overload and pressure overload due to left-toright shunt-induced myocardial injury: Evaluation using a highly sensitive cardiac troponin-I assay in children with congenital heart disease. Circ J., 75: 2213-2219.

4. Hoff J, Wehner W, Nambi V (2016): Troponin in cardiovascular disease prevention: Updates and Future Direction. Curr Atheroscler Rep., 18 (3): 1216.

5. Takeda S, Yamashita A, Maeda K (2003): Structure of the core domain of human cardiac troponin in the $\mathrm{Ca}^{2+}$ saturated form. Nature, 424: 35-41.

6. Solinca B (2004): Cardiac troponins. Med Pr., 10: 133-136.

7. Jaffe A, Wu A (2012): Troponin release--reversible or irreversible injury? Should we care? Clin Chem., 58: $148-50$.

8. Shah A, Feraco A, Harmon C et al. (2009): Usefulness of various plasma biomarkers for diagnosis of heart failure in children with single ventricle physiology. Am J Cardiol., 104: 1280-1287.

9. Keller T, Zeller T, Peetz D et al. (2009): Sensitive troponin I assay in early diagnosis of acute myocardial infarction. N Engl J Med., 361: 868-877.

10. McCarthy C, Yousuf O, Alonso A et al. (2017): High-Sensitivity Troponin as a Biomarker in Heart Rhythm Disease. Am J Cardiol., 119 (9): 1407-1413.

11. Twerenbold R, Reichlin T, Mueller C (2010): Clinical application of sensitive cardiac troponin assays: Potential and limitations. Biomarkers Med., 4: 396-401.

12. Hafez M, Morsy S, Mahfoz $R$ et al. (2015): Myocardial injury in children with unoperated congenital heart diseases. https://doi.org/ $10.1155 / 2015 / 104818$

13. Ghaderian M, Emami A, Samir M et al. (2014): Lipid and Glucose Serum Levels in Children with Congenital Heart Disease. J Teh Univ Heart Ctr., 9 (1): 20-27.

14. Brickner E, Hillis D, Lange $R$ (2000): Congenital heart disease in adults. N Engl J Med., 342 (4): 256263.

15. Heresi G, Tang W, Aytekin M et al. (2012): Sensitive cardiac troponin I predicts poor outcomes in pulmonary arterial hypertension. Eur Respir J., 39 (4): 939-944.

16. Korraa A, Ezzat M, Bastawy M et al. (2012): Cardiac troponin I levels and its relation to echocardiographic findings in infants of diabetic mothers. Ital J Pediatr., 38 (1): 39-42.

17. El-Khuffash A, Davis PG, Walsh K et al. (2008): Cardiac troponin $\mathrm{T}$ and $\mathrm{N}$-terminal-pro-B type natriuretic peptide reflect myocardial function in preterm infants. Journal of Perinatology, 28(7): 482485. 